\title{
SACRU ȘI PROFAN ÎN ATRIBUIREA PRENUMelor din T,ARA Chioarului
}

\author{
MARIA-MARA IgnAT \\ Universitatea Tehnică din Cluj-Napoca, \\ Centrul Universitar Nord Baia Mare, România

\section{Sacred and profane in the tradition of giving first names in the Land of Chioar}

\begin{abstract}
Being a link between tradition and modernity as well as between sacred and profane, names offer a clear picture of the past and the present. They successfully provide a picture of the lives of individuals and communities.

The present paper aims at analyzing the way in which name-giving either pertains to a tradition by preserving Romanian names, or is anchored in modernity, through the adoption of foreign designations. Thus, there is continuity in giving first names inspired by the Bible, but the strong influence of the West may also be observed especially after 1989 .

By studying the first names in the Civil Registers of the settlements in the Land of Chioar, this research is, in fact, a synchronous and diachronic analysis, highlighting name givers' attitudes towards globalization.
\end{abstract}

Keywords: first name, tradition, modernity, sacred, profane.

\section{Considerații preliminare}

În lucrarea de faţă, vom analiza modalitatea în care actul numirii se încadrează fie într-o tradiție prin conservarea prenumelor românești, fie este ancorat în modernitate, prin adoptarea unor denominații străine. Astfel, vom remarca o continuitate în atribuirea numelor de botez de inspirație biblică, observând, totodată, și puternica influență a Occidentului, survenită, în special, începând cu secolul al XVIII-lea.

Având ca material de studiu prenumele consemnate în Registrele Stării Civile aferente localităților Țării Chioarului ${ }^{1}$, prezenta cercetare este, în fapt, o analiză sincronică și diacronică a acestora, reliefând modul în care atitudinea nominatorului se înscrie sau nu în trendul globalizării.

\section{Premise teoretice}

Văzut ca factor ordonator al vieții și activității omenești, numele reprezintă

1 Țara Chioarului este situată în sud-vestul județului Maramureș, ținutul fiind delimitat în vest de râul Someș, în est de dealurile Șatra și Pietriș, care separă depresiunea Băii Mari de Țara Lăpușului, la nord de lanțul munților Oaș, Gutâi și Țibleș, iar la sud, de platforma someșeană. 
modalitatea de identificare şi recunoaștere a tot ceea ce ne înconjoară, motiv pentru care se înscrie pe lista principalelor preocupări din lumea onomasticii, fiind subiect de studiu pentru lingvişti, filozofi, demografi, sociologi, antropologi.

Apărut ca o necesitate, actul denominativ este amintit încă de la începutul lumii când: „a pus Adam nume tuturor animalelor și tuturor păsărilor cerului şi tuturor fiarelor sălbatice" (Geneza 2: 20). De atunci și până în prezent s-a observat că acest proces suferă o permanentă modificare, numele înregistrând schimbări în funcție de semnificațiile atribuite, dar și de cultura în care apare.

Golopenția-Eretescu (1972, I: 145, apud Felecan D. 2010: 138) înțelege prin numire atât actul de atribuire de nume, care poate fi ritual / oficial / convențional (botezarea) și nonritual / neoficial / neconvențional (poreclirea, supranumirea), cât și actul de utilizare a unui nume preatribuit. De asemenea, Felecan D. (2011:256) recunoaște ca produse ale actului de numire neconvențională următoarele categorii antroponimice: porecla, supranumele (individual și de grup), pseudonimul, hipocoristicul și nickname-ul.

După cum observă Felecan D. (2012: 80), ,actul de numire oficială, pentru a fi recunoscut la nivelul întregii comunități, se desfăşoară în respectul unui algoritm lingvistic (nou-născutul primește un nume) și extralingvistic (identitatea nominală este atribuită, printr-un ritual, de către preot și recunoscută / confirmată într-un nomenclator de către ofițerul Stării Civile). Produsele actului mai sus descris se numesc nume oficiale”. Astfel, în momentul atribuirii rituale de nume vom avea următoarele instanțe:

- nominatorul, reprezentat de cei care aleg numele copilului, de regulă părinții acestuia, care, conform lui Ionescu-Pérez (2007: 220), sunt în măsura de a stabili structura generală a formulei antroponimice, numărul și caracteristicile componenților funcționali.

- validatorul, rol ce revine atât ofițerului de Stare Civilă prin trecerea numelui în nomenclator, cât și preotului, prin botezul primit în biserică.

- numitul, anume cel căruia i se atribuie numele respectiv.

Atribuirea prenumelui unui nou-născut este un act de voință din partea părinților, întrucât aceștia pot alege, într-un mod subiectiv, dacă denominația descendenților se va înscrie pe linia tradiției sau dacă va fi adaptată în trendul actual. Din dorința oamenilor de a se individualiza, numele vechi sunt concurate de cele „la modă”, fapt care supune desemnarea unui proces de înnoire, numele fiind, astfel „,domeniul cel mai penetrabil al antroponimiei, cel mai receptiv în materie de influențe străine" (Vascenco 1969: 124).

Întrucât „a învesti cu nume este, probabil, activitatea subiectivă și conștientă de creație lingvistică cea mai angajantă din punctul de vedere al responsabilității agentului față de evoluția pacientului la nivel nominal” (Felecan D. 2014: 493), oamenii au manifestat $\mathrm{o}$ atenție sporită pentru denominația dată urmașilor. Astfel, procesul numirii s-a fundamentat pe criteriul nomen est omen, căruia Iorgu Iordan (1979: 42) i-a găsit traducerea „de numele omului depinde soarta lui”. În acest fel, lingvistul scoate în evidență faptul că denominația este, de fapt, o urare pentru cel care îl poartă: „de aceea se alegeau nume care exprimau în modul cel mai clar dorința părinților ca odrasla lor să fie personificarea a tot ce este bun, frumos, înălțător etc." (Ibidem: 42), numele și 
purtătorul acestuia fiind într-o strânsă legătură, asociată de Iorgu Iordan (Ibidem: 42) cu aceea „de la cauză la efect, de fapt de la dorință până la realizarea dorinței”.

\section{Antroponime chiorene între sacru și profan}

Dat fiind faptul că „numele constituie o părticică din tradiție, din istoria țării, ele dau informații asupra culturii și asupra modului de viață în general” (Graur 1965: 9), însă „dintre toate elementele limbii, cele mai legate de evoluția societății sunt numele de persoană, ele se înlocuiesc mult mai ușor decât numele comune” (Ibidem: 9), fiind, astfel, supuse modificării.

De-a lungul vremii, numele de botez și-au pierdut încărcătura semantică, rămânând doar cu funcția de identificare. Chiar dacă pentru nominator are, de regulă, valoare afectivă, denominația nu mai poartă cu sine o încărcătură magică, ci reprezintă doar un mod de individualizare a celui desemnat. Astfel, „faptul că în mod normal, referentul unui nume propriu este unic, permite ideea funcționării lui ca simplă etichetă atașată obiectului, ca și cum acesta ar putea avea un referent, dar nu și un sens, sau, în formularea lui John Stuart Mill, o denotație, dar și o conotație” (DEȘL: 239).

Pentru cele dintâi prenume s-au folosit cuvinte biblice și calendaristice. În acest sens, analizând registrele cu nume regăsite în zona cercetată, observăm cum în secolul al XIX-lea principalele prenume atribuite nou-născuților erau, cu precădere, de inspirație religioasă. Dintre acestea, amintim: Alexandru, Andrei, Anton, Constantin, Dumitru, Gavril / Gavrilă, Gheorghe, Ioan, Ilie, Mihai, Nicolae, Pavel, Petru, Simion, Ștefan, Toader, Toma, Vasile / Vasalie - la bărbați, iar Alexandrina, Ana, Constantina, Elena, Elisabeta, Eudochia, Ioana, Maria, Parasca / Paraschiva, Sava, Sofia - la femei. Ulterior, aria acestora s-a extins, intrând și nume străine, porecle, supranume, toponime, nume de meserii etc., iar, ca urmare, în deceniul al XX-lea se vor întâlni și prenume ca: Adrian, Alin, Augustin, Aurelian, Claudiu, Cornel, Costel, Cristian, Dorin, Doru, Emil, Emilian, Eugen, Florian, Florin, Gabriel, George, Iulian, Iuliu, Laurențiu, Levente, Liviu, Ludovic, Marcel, Marian, Marius, Octavian, Ovidiu, Paul, Remus, Robert, Romeo, Sebastian, Sergiu, Silviu, Sorin, Stelian, Tiberiu, Traian, Valentin, Valer, Victor, Viorel, Virgil ș.a. - pentru băieți, dar și: Adela, Adina, Adriana, Alina, Anamaria, Aneta, Angela, Aurelia, Aurica, Bianca, Camelia, Carmen, Catinca, Cecilia, Claudia, Constanța, Corina, Cornelia, Cristina, Daniela, Delia, Diana, Domnica, Dorina, Eleonora, Elvira, Emilia, Erika, Eva, Felicia, Florentina, Florina, Gabriela, Georgeta, Georgiana, Gina, Ionela, Ionica, Iulia, Iuliana, Lăcrămioara / Lăcrimioara, Laura, Lavinia, Leontina, Lidia, Liliana, Lina, Livia, Loredana, Lucia, Luminița, Marcela, Mariana, Marilena, Marinela, Mihaela, Mioara, Mirela, Monica, Natalia, Nicoleta, Olimpia, Otilia, Paula, Paulina, Petronela, Ramona, Rodica, Rozalia, Sabina, Silvia, Simona, Sorina, Stela, Steliana, Steluța, Susana, Terezia, Valentina, Valeria, Violeta, Viorica, Virginia ș.a. - pentru fete.

În zilele noastre, denominațiile de sorginte sacră sunt în regres, apărând doar în situația când se moștenește prenumele tatălui ori al înaintașilor sau al unei rudenii, fapt dovedit de preferința nominatorilor pentru nume ca: Adonis, Ares / Aris, Ayan, Bruno, Charles, Dorian, Edgar, Elian, Elvis, Enrique, Fabrizio, Giancarlo, Gianluca, Igor, 
Kevin, Lorenzo, Loius, Narcis, Norbert, Orlando, Patric, Ricardo, Robert, Samir / Semir ș.a. - la băieți, dar și Alice, Amaia, Annabel, Carola, Consuelo, Edith, Electra, Esmeralda, Fernanda, Isabel / Isabela / Isabella / Izabela, Jennifer, Kelly, Luisa / Luiza, Maya, Nerea, Ophelia, Rihana, Soledad, Thea ș.a. - la fete.

Observăm, deci, că, în alegerea prenumelor actuale, părinții din Țara Chioarului, ca peste tot în lume, sunt determinați atât de factori estetici, cât și de modă și de dorința de imitație. Astfel, numele de botez tradiționale, sacre pierd teren în faţa celor laice, modernitatea punându-şi tot mai mult amprenta asupra procesului denominativ.

În mentalul colectiv, a atribui un nume împrumutat înseamnă a-i conferi unicitate nou-născutului, a-l singulariza în cadrul grupului social, a-l distinge de ceilalți membri. Dorința individualizării survine, în special, după anul 1989, întrucât, având acces la modernitate, oamenii își doresc o schimbare chiar și la nivelul desemnării. Mass-media și emigrarea conaționalilor în Occident favorizează adoptarea unor prenume străine, de inspirație profană, care oferă un colorit aparte sistemului denominativ chiorean. Astfel, „laicizarea se manifestă nu numai prin eliminarea unor nume și înlocuirea lor cu altele, fără nicio legătură cu creștinismul, ci și prin renunțarea la factorul religios în alegerea acestora. Motivele care acționează astăzi și determină alegerea prenumelor sunt prin excelență laice” (Ionescu 1975: 15).

La nivel antroponimic, anul 1989 a reprezentat începutul schimbării, întrucât oamenii își doreau cu orice preț să iasă din tiparele autohtone, să se debaraseze de tot trecutul „ostil liberei opțiuni [...] de a-şi hotărî soarta” (Felecan O. 2009a: 73), râvnind unicitate și originalitate. În acest sens, apariția unor posturi TV si radio private a constituit o importantă sursă de inspirație antroponomastică. Personajele care impresionau prin frumusețea numelui, prin aspectul fizic sau ale căror povești emoționau telespectatorii își lăsau amprenta asupra oamenilor de rând, dornici să-și boteze copiii asemeni idolilor.

Grăitor în ceea ce privește antroponimia chioreană este și fenomenul emigrării, care influențează încă o dată preferința pentru numele profane, în detrimentul celor sacre. Problematica de față are o dublă explicație: pe de o parte, românii aleg prenume specifice țării „primitoare” din dorința adaptării, întrucât insul poate fi catalogat de societate și după prenumele pe care îl poartă, fiind identificat cu trăsăturile nației originare. Pe de altă parte, călătoriile ocazionale sau munca în Occident au marcat opțiunile denominative prin aproprierea unor nume de botez străine, și, deci, la modă. Astfel, deschiderea lingvistică, în general, și cea antroponimică, în particular, pune în lumină alăturarea unor „nume de botez extrem de noi la seria ce a lărgit inventarul în ultimele decenii”, constituind „noul din antroponimia rurală” (Felecan O. 2006: 338).

Deci, „o tendință generală în sistemul de denominație personală de pretutindeni este aceea a modernizării numelor de botez” (Pașca 1936: 30), întrucât „criteriul estetic oferă posibilitatea unei alegeri mai elastice a prenumelor, ducând astfel la o împrospătare a fondului de prenume existent" (Teiuș 1962: 183).

Totuși, comunitățile chiorene, cu precădere cele din mediul rural, păstrează încă viu și obiceiul de a oferi copiilor nume de sfinți. Tradiția, codul de legi nescrise care 
continuă să țină piept tendințelor novatoare, se impune prin alegerea unor prenume sacre atribuite, pe de o parte, în virtutea faptului că cel botezat se află sub protecția sfântului al cărui nume îl poartă, denominația primită devenind un liant între el și divinitate. Pe de altă parte, aproprierea prenumelor calendaristice / hagiografice oferă, în cadrul familiilor, o continuitate antroponimică. Deci, dacă bunicul poartă numele de Dumitru, este necesar ca și fiul și nepotul să se numească astfel, deoarece, probabil, și antecesorii acestora au avut acest prenume.

Membrii comunitățiilor chiorene manifestă dorința de a respecta în egală măsură tradiția și inovația, astfel că asistăm la un fenomen interesant pentru lingviști și sociologi și anume, împletirea sacrului cu profanul, un fapt înfățișat prin exprimarea voinței părinților și concretizat prin apariția prenumelor duble sau triple.

În consecință, „indiferent de epoca la care ne referim, sistemul antroponimic reflectă indubitabil transformări sau tendințe care caracterizează societatea în general, ori grupurile sociale, în particular” (Oancă 1996: 7), așa că orice noutate apărută la nivelul desemnării trebuie văzută ca un fenomen social, întrucât un nume nou apărut în cadrul unei comunități poate fi preluat cu ușurință de mai mulți membri ai acesteia, devenind, într-un interval de timp relativ scurt, un trend în cadrul grupului social respectiv.

\subsection{Nume de botez biblice / hagiografice}

Prin botez, orice creștin primește un nume, care nu este dat la voia întâmplării, chiar dacă, de cele mai multe ori, aceasta este impresia. Acordarea unui prenume este și a fost dintotdeauna un act motivat, astfel că alegerea, atribuirea sau schimbarea lui sunt determinate de măsura în care nominatorii își aproprie sau nu tiparele personajelor din Sfânta Scriptură.

Chiorenii folosesc o serie de prenume inspirate din Biblie, nădăjduind că odraslele lor se vor afla sub protecția divinității și vor fi ferite de orice rău. Astfel, în ciuda faptului că tot mai mulți oameni s-au îndepărtat de credință, factorul religios dictează și astăzi opțiunea denominatorilor, mai ales când pruncul este născut în ziua celebrării unui sfânt. Din dorința de a respecta atât cutuma tradițional-religioasă², cât și moda, părinții optează pentru prenume ce ar satisface ambele doleanțe ajungându-se la structuri nominative hibride: Kevin-Ștefan, Roberto-Ioan, Alessia-Maria, Jessica-Ionela etc.

Alegerea prenumelor simple, duble sau triple rămâne la latitudinea strictă a denominatorilor, însă cert este că, indiferent de alegerea lor, sacrul este păstrat în antroponimie prin numărul mare de ocurențe precum: Andrei, Antonie, Constantin, Ciprian, Dumitru / Dimitrie, David, Daniel, Efrem, Gheorghe, Grigore, Ioan, Iosif, Ilie, Luca, Matei, Marcu, Nectarie, Nicolae, Pavel, Petru, Stelian, Ștefan, Toma, Valentin ș.a. - la băieți; Alexandra, Ana, Cipriana, Daniela, Dumitra, Elena, Elisabeta, Filofteia, Gabriela, Georgiana, Ioana, Irina, Lucia, Maria, Magdalena, Mihaela, Nectaria, Paula, Petra, Sara, Sofia, Tatiana, Veronica ș.a. - la fete.

2 „La place du nom dans les traditions juive et chrétienne est monumentale et influencera en conséquence des siècles de pensée. La Bible nous fournit par exemple un thème toujours présent, celui de la présence organique du nom" (Vaxelaire 2005: 412). 
În atribuirea prenumelor de inspirație biblică importantă este și confesiunea nominatorului, întrucât, în funcție de aceasta, va prefera sau nu anumite denominații. Dacă (neo)protestanții aleg cu precădere nume de botez regăsite în Vechiul Testament, catolicii și ortodocșii optează pentru cele hagiografice.

Astfel, dat fiind faptul că printre indivizii din Țara Chioarului se numără și penticostali, baptiști, martori ai lui Iehova ${ }^{3}$ etc., în inventarul prenumelor regăsim și denominații vetero-testamentare ca: Abigel, Avram, Beniamin / Benjamin / Veniamin, Cadmiel, Caleb, Elias, Ezekiel, Ioil / Ioiel, Ionadab, Ionatan, Iov, Isaia, Joseph, Nathan, Nathanael, Ruben, Samuel, Saul, Tobias, Timotei ș.a. - la băieți; iar Abigail, Damaris, Debora(h), Eklesia, Estera, Lidia, Miriam, Persida, Priscila, Rahela, Ruhama, Rut(h), Sara(h), Semida / Simida, Tabita ș.a. (v. Bălan-Mihailovici 2003) - la fete. Prenumele de față sunt acordate de nominatori care își însușesc atributele personajelor din Biblie: „Lipsit de un inventar specific, protestantismul se caracterizează prin refuzul numelor de sfinți catolici sau ortodocși și acceptarea largă a numelor din Vechiul Testament" (Ionescu Pérez 2007: 226). În acest sens, Oliviu Felecan prezintă trei funcții simbolice ale prenumelor, dintre care primele două pun în lumină modalitățile de acordare a nominațiilor nou- și veterotestamentare în cadrul unui grup social (neo)protestant:

- funcția separatoare, care-i „individualizează pe cei ce poartă prenume neobișnuite de restul oamenilor";

- funcție unificatoare, ce „reunește purtătorii unor nume de botez într-un grup (familia) sau într-o colectivitate (satul, de ex.)";

- funcție de prestigiu, care se bazează pe ideea de faimă, întrucât „cei clasaţi pe o poziție inferioară în comunitate vor tânji spre imitarea modelelor, în timp ce persoanele aflate în vârful ierarhiei sociale vor încerca să se diferențieze (și) antroponimic de mase" (Felecan O. 2013: 93-94).

\subsection{Nume de botez de ispirație profană}

Slăbirea rolului religiei în societate a însemnat pentru antroponimie impunerea prenumelor laice. În țara noastră, sursa de inspirație a denominațiilor în discuție a fost, de cele mai multe ori, un substantiv comun cu valoare simbolică, întrucât „din punctul de vedere al structurii semantice originare, numele de inspirație profană provin din cuvinte comune sau sintagme cu funcție de a descrie" (Ionescu 1975: 14). Amintim în acest sens denominații precum: Brândușa, Bujor, Faur, Firicel, Garoafa, Lăcrămioara, Luminiţa, Mugurel, Viorel, Viorica (v. Constantinescu 1963 și Tomescu et al. 2001: 457).

Neavând pretenția de a fi realizat o listă completă a numelor de inspirație profană, redăm principalele categorii (v. Ionescu 1975 și Iordan 1983) în care se pot încadra prenumele laice întâlnite în antroponimia chioreană ${ }^{4}$ :

3 Datele recensământului din 2011 arată că în județul Maramureș coexistă numeroase etnii și confesiuni religioase (astfel, vezi http://www.ecoduri.com/recensamantul-populatiei/ Maramures.php\# etnie).

4 Pentru clarificare v. Constantinescu 1963 și Ionescu 1975. 
- o particularitate fizică sau morală: Alfred, Aurora, Bianca, Casandra, Clara, Edita, Ernest, Ferdinand, Grațiela, Linda, Mirabela, Mirela, Roxana, Smaranda;

- rangul sau poziția socială: Despina, Isolda, Veturia, Voicu, Voica;

- poziția în cadrul familiei: Octav / Octavia, Septimiu;

- ocupații, îndeletniciri, meserii: Faur;

- momentul naşterii: Dan / Dana, Ozana;

- regnul vegetal, mineral ori animal': Bujor, Coralia, Crina, Dalia, Esmeralda, Firicel, Garofița, Ivona, Lăcrimioara, Margareta, Mălin / Mălina, Oliviu / Olivia, Viorica;

- atitudinea sau sentimentul părinților faţă de noul născut: Dragoș, Gloria, Letiţia, Mara, Nadia, Radu, Raluca;

- substantive comune din diverse arii semantice: Doina, Horea, Mitrofan, Ofelia, Sultana, Năstase.

\subsection{Nume de botez „la modă”}

Pornind de la premisa că limba română a fost și este supusă înnoirii prin disponibilitatea de a prelua termeni străini cu scopul dezvoltării lexicului existent, putem afirma că se situează în categoria „celor mai ospitaliere din Europa, ceea ce se traduce pe tărâm antroponimic printr-o deschidere majoră faţă de prenumele străine, indiferent de epoca istorică” (Felecan O. 2009a: 67).

A vorbi despre apariția prenumelor neologice înseamnă a te raporta la „moda lingvistică”, un factor care a contribuit hotărâtor la diversitatea denominației existente în Țara Chioarului, provocând schimbări și substituții în sistemul onomastic. Trendul în numire „se constituie ca un produs al tuturor condițiilor de viață ale omului (economice, sociale, politice și culturale)" (Zăbavă 2009: 158) și este, după cum precizează şi Tatiana Petrache în Dicționarul enciclopedic al numelor de botez (1998: 12), „un factor determinant în antroponimie care nu a scutit de transformări și substituții sistemul onomastic al vreunui popor. «Moda făcu pe gali să părăsească vechile nume și să le accepte pe cele romane. Când vin barbarii, galo-romanii, la rândul lor, iau nume folosite de aristocrația francă; mai târziu, burghezul botează copiii cu nume folosite în familiile nobile, țăranul imită pe burghez»” (Dauzat, apud Petrache 1998: 12).

Ca o tendință generală a perioadei actuale, se constată o preferință aparte pentru numele străine în detrimentul celor tradiționale / hagiografice românești, observânduse, astfel:

5 „E uneori foarte enigmatică evoluția semantică a unor nume provenite de la nume de arbori și plante. Cu simțul său intuitiv, poporul, care trăiește în mijlocul naturii, caută să pătrundă tainele acesteia, încearcă mereu să cunoască proprietăţile lucrurilor care-l înconjoară” (Pașca 1936: 105).

6 S-a optat pentru moda lingvistică „prin analogie cu cea vestimentară, întrucât și aici funcționează același joc între imuabil și efemer, între aventura novatoare și cumințenia tradiționalistă, în aceeași atmosferă de mimetism frenetic, dar și de contestare vehementă. Ca și în vestimentație, nu tot ce se poartă la un moment dat este bun, corect și frumos, dar nici nu trebuie automat respins orice iese din obişnuința noastră lingvistică sau contravine gustului personal” (G. Gruiță 2006: 9). 
- prenume de origine italiană: Alesia, Alesandra, Alessandra, Alessandro, Angelo, Antonio, Beatrice, Claudio, Cristiano, Dario, Davide, Fabio, Geanina, Giovanni, Giulia, Giuliana, Giuseppe, Lorenzo, Luciano, Luisa, Marco, Mario, Matteo, Paolo, Roberto, Riccardo, Romina, Sergio, Stefano, Valentino.

- prenume de origine spaniolă: Alberto, Alicia / Alisia, Amaia, Carlos, Carmelo, Dario, Diego, Dolores, Ernesto, Miguel, Luis, Rosalinda, Soledad, T(h)alia.

- prenume de origine franceză: Alice, Bernadette, Celine, Denis, Dominique, Eveline, Ivone, Jasmin, Julien, Madelaine, Melanie, Michel, Nicole, Nicolas, Raphael, Susane, Vanessa, Viviane.

- prenume de origine engleză: Andy, Betty, Brenda, Christian, Edith, Edward, Elisabeth, Elvis, Evelyn, Kate, Kevin, Jack, Jessica, Jonathan, Patrik, Ryan, Wiliams.

- prenume de origine germană: Alfred, Dieter, Egmond, Emeric, Fred, Gerrard, Hans, Hilda, Hubert, Klaus.

- prenume de origine maghiară (v. Felecan O. 2009b: 116-131): Attila, Csaba, Csilla, Eniko, Gellert, Gizella, Ibolya, Kinga, Lászlo, Orsolya, Szabolcs, Szilard, Tamas, Zoltan.

Comparând influența limbilor romanice cu a celor germanice, observăm că, deși chiorenii preferă prenumele italienești, optează tot mai des şi pentru cele englezești, dovadă că anglicismele au un puternic impact și asupra acestora. Nu de puține ori, denominațiile străine se împletesc în cazul prenumelor duble sau triple, înregistrânduse combinații între limbile:

- italiană-engleză / engleză-italiană: Antonio-Patrik, Luisa-Edith, Gianina-Brenda, Jessica-Beatrice, Wiliams-Lorenzo.

- italiană-franceză / franceză-italiană: Angelo-Nicolas, Dario-Michel, DominiqueLeonardo, Giulia-Alice, Marco-Raphael.

• italiană-spaniolă / spaniolă-italiană: Esmeralda-Geanina, Fabio-Diego, Luis-Stefano.

- franceză-spaniolă / spaniolă-franceză: Dominique-Ernesto, Denise-Soledad, Eduardo-Julien, Nicolas-Antonio.

În ceea ce privește opțiunea pentru aceste prenume, se observă cum populația de la oraș este mai deschisă spre nou, spre împrumuturile din alte limbi, fapt pentru care, de cele mai multe ori, alături de un nume tradițional românesc, se află unul modern, exotic. Această practică este valabilă și în mediul rural, chiar dacă, uneori, sătenii se dovedesc a fi mai conservatori, preferând denominațiile comune, des întâlnite în cadrul grupului social din care fac parte. Astfel, fiind un produs al contactului lingvistic și cultural, modernitatea în desemnare conferă uniformitate antroponimiei, dând un aspect cosmopolit onomasticonului chiorean.

\section{4. Împletirea tradiției cu modernitatea}

Din dorința de a îmbina autenticul cu tentațiile ${ }^{7}$ vremii, oamenii au optat pentru

7 „Tradition refers to a broad spectrum of socially acquired behavioral restrictions or 
prenumele duble sau triple, care, de cele mai multe ori, au în componența lor atât un nume biblic / hagiografic, cât și unul modern fapt care permite, datorită varietății lor, următoarea structură (v. Ionescu 2001):

- Nume calendaristic + nume calendaristic: Ana-Maria, Filofteia-Elena, GavrilNicolae, Ilie-Luca, Ioan-Ștefan, Maria-Elena, Maria-Elisabeta, Maria-Magdalena, PetruAnton, Simion-Alexandru, Vasile-Simeon etc.;

- Nume calendaristic + nume de origine cultă: Andrei-Flaviu, Gabriel-Igor, IoanValeriu, Maria-Francisca etc.;

- Nume calendaristic + nume de origine occidentală: Ana-Iolanda, Florin-Nicolas, Maria-Genoveva, Matei-Roland, Pavel-Ludovic, Ștefan-Orlando etc.;

- Nume calendaristic + nume mitologic: Filofteia-Diana, Ștefan-Artemis, VasileAres etc.;

- Nume calendaristic + corespondentul feminin al numelui hagiografic masculin: Cristina-Mihaela, Marta-Constantina, Maria-Andreea, Maria-Mihaela etc.;

- Corespondentul feminin al numelui hagiografic masculin + corespondentul feminin al numelui hagiografic masculin: Alexandrina-Ionela, Dumitriţa-Andreea, Gabriela-Mihaela, Ionela-Manuela, Mihaela-Antonela etc.

În ciuda faptului că populația din Țara Chioarului dorește o conservare a vechilor obiceiuri, observăm cum, la nivel antroponimic, inventarul prenumelor clasice este îmbogăţit de cele occidentale, tendință ce prinde contur și în comunitățile rurale. Chiar dacă „mediul urban vădește o deschidere către nou, către împrumuturile din alte limbi” (Felecan O. 2009a: 68), se poate observa că și în lumea satelor există formule denominative în componența cărora se remarcă atât nume de botez românești, cât și preluate din limbile romanice sau din cele germanice. Exemplificăm: Ana-Geanina (prenume româno-italian), Eveline-Maria (prenume francez-român) sau Richard-Mario-Daniel (prenume englez-italian-român) etc.

\section{Considerații finale}

Variabilitatea prenumelor la românii din Țara Chioarului oglindește istoria comunității, schimbările sociale, contactul cu alte populații, credințele, influența globalizării. Odată cu modernitatea, nominatorii se pot inspira din toate părțile mapamondului: Armando, Matilde, Tifany, Zoltan ș.a. Împletirea tradiției cu opțiunea părinților, fenomen care se materializează prin acordarea prenumelor duble sau triple, pare a reflecta o tranziție între vechi și nou, trecut și prezent, sacru și profan: David-Santiago, Ioan-Roberto, Jennifer-Ana-Isaura, Kitti-Maria ș.a.

Reflectând legătura directă a omului cu lumea în ansamblul ei, se observă atât conservarea unor nume autentice, de factură religioasă, cât și adoptarea altora din dorința de schimbare. Veche sau nouă, desemnarea are o funcție fundamentală: separă și distinge indivizii. Conform acestui principiu, a deține informații privitoare la un

obligations. Like temptation, tradition is both a qualitative and quantitative variable, encompassing both the contents and strength of a group's practices" (Douglas 2010: 71). 
popor presupune și o cunoaștere a idiomului și, implicit, a modalității de oferire a numelor, în general, și a celui de botez, în particular.

\section{Bibliografie}

Bălan-Mihailovici, A. 2003. Dicționar onomastic creștin. Repere etimologice și martirologice. București: Editura Minerva.

Biblia sau Sfânta Scriptură. 1975. București: Editura Institutului Biblic și de Misiune al Bisericii Ortodoxe Române.

Constantinescu, N. A. 1963. Dicționar onomastic românesc (DOR). București: Editura Academiei.

Douglas, A. 2010. Temptation, Tradition, and Taboo: A Theory of Sacralization. Sociological Theory 28: 1 .

Ducrot, Oswald, J.-M. Schaeffer. 1996. Dicționar enciclopedic al științelor limbajului (DEȘL). București: Editura Babel.

Felecan, D. 2010. Aspecte ale polifoniei lingvistice. București: Editura Tritonic.

Felecan, D. 2011. Antroponime neconvenționale româneşti: tipare de construcție şi funcție discursivă - premise ale cercetării. În Studii de dialectologie, istoria limbii şi onomastică. Omagiu domnului Teofil Teaha, M. Marin şi D. Răuţu (coord.), 253-266. Bucureşti: Editura Academiei Române.

Felecan, D. 2012. Antroponimele neoficiale (AN) - realizări discursive ale „nivelului individual” al limbajului / Unofficial Anthroponyms - Discoursive Accomplishments of the "Individual Levels" of the Language. Philologia 13: 79-87.

Felecan, D. 2014. Identitate și alteritate în actul de numire [Identity and alterity in name-giving]. În The Proceedings of the International Conference Communication, Context, Interdisciplinarity. vol. 3, 490-496. http://www.upm.ro/cci3/CCI-03/Lds/Lds\%2003\%2060.pdf (accesat în 10 august 2017).

Felecan, O. 2006. Vechi și nou în antroponimia maramureșeană. În Lucrările celui de-al XIIlea Simpozion Național de Dialectologie, Baia Mare 5-7 mai 2006, 333-341. Cluj-Napoca: Editura Mega.

Felecan, O. 2009a. Interferențe multietnice reflectate în antroponimia maramureşeană (19872007). Buletin Științific 18: 61-71.

Felecan, O. 2009b. Interferențe româno-maghiare în antroponimia din nord-vestul României. În Limba română în context european, 116-131. Cluj-Napoca: Editura Mega.

Felecan, O. 2013. Un excurs onomastic în spațiul public românesc actual. Cluj-Napoca: Mega, Argonaut.

Graur, A. 1965. Nume de persoane. Bucureşti: Editura Ştiințifică.

Gruiță, G. 2006. Moda lingvistică 2007. Norma, uzul şi abuzul. Pitești: Editura Paralela 45.

Ionescu, Ch. 1975. Mica Enciclopedie Onomastică (MEO). București: Editura Enciclopedică Română.

Ionescu, C. 2001. Dicționar de onomastică. Bucureşti: Editura Elion.

Ionescu Pérez, P. C. 2007. Concepte, metodologie şi terminologie în antroponimia romanică. În Limba română, limbă romanică. Omagiu acad. Marius Sala la împlinirea a 75 de ani, S. Reinheimer Rîpeanu și I. Vintilă-Rădulescu (coord.), 215-234. București: Editura Academiei Române.

Iordan, I. 1979. Influența modei asupra numelor de persoană. Limba Română 18 (1): 41-50. 
Iordan, I. 1983. Dicționar al numelor de familie românești. București: Editura Științifică și Enciclopedică.

Oancă, T. 1996. Nume standard şi variante antroponimice. Probleme de terminologie. Studii și Cercetări de Onomastică 2 (2): 45-52.

Pașca, Ș. 1936. Nume de persoane și nume de animale din Țara Oltului. București.

Petrache, T. 1998. Dicționar enciclopedic al numelor de botez cu un tabel alfabetic al sfinților ortodocşi. București: Editura Anastasia.

Sala, M. (coord.). 2001. Enciclopedia limbii române. București: Editura Elion.

Teiuş, S. 1965. Modernizarea sistemului de denominație cu prenume în Valea Bistriței (Bicaz). Cercetări de Lingvistică 10 (1): 179-185.

Vascenco, V. 1969. Asupra elementelor rusești din antroponimia unor limbi altaice și libero-caucaziene. Studii de slavistică: 119-128.

Vaxelaire, J. L. 2005. Les noms propres. Une analyse lexicologique et historique. Paris: Honoré Champion Éditeur.

Zăbavă, E.-C. 2009. Prenumele român între modă și tradiție. Studii de Știință și Cultură 4 (19): 158-162.

\section{Site-uri}

http://www.ecoduri.com/recensamantul-populatiei/Maramures.php\#etnie (accesat în 25 iunie 2017). 